\title{
Pro-Inflammatory Effects of Interleukin-17A on Vascular Smooth Muscle Cells Involve NAD(P)H- Oxidase Derived Reactive Oxygen Species
}

\author{
Eweline Pietrowski Bianca Bender Jula Huppert Robin White \\ Heiko J. Luhmann Christoph R.W. Kuhlmann \\ Institute of Physiology and Pathophysiology, University Medical Center of the Johannes Gutenberg University, \\ Mainz, Germany
}

\section{Key Words}

Interleukin-17 · NAD(P)H-oxidase • Reactive oxygen species • Vascular smooth muscle

\begin{abstract}
$T$ cells are known for their contribution to the inflammatory element of atherosclerosis. Recently, it has been demonstrated that the Th17 derived cytokine IL-17 is involved in the pro-inflammatory response of vascular smooth muscle cells (VSMC). The aim of the present study was to examine whether reactive oxygen species (ROS) might be involved in this context. The effect of IL-17A on ROS generation was examined using the fluorescent dye $2^{\prime} 7^{\prime}$-dichlorodihydrofluorescein $\left(\mathrm{H}_{2} \mathrm{DCF}\right)$ in primary murine VSMC. IL-17A induced an increase in $\mathrm{H}_{2} \mathrm{DCF}$ fluorescence in VSMC, and this effect was blocked by the $\mathrm{NAD}(\mathrm{P}) \mathrm{H}$-oxidase inhibitor apocynin and siRNA targeting Nox2. The p38-MAPK inhibitors SB203580 and SB202190 dose-dependently reduced the IL-17A induced ROS production. The IL-17A induced release of the proinflammatory cytokines IL-6, G-CSF, GM-CSF and MCP-1 from VSMC, as detected by the Luminex technology, was completely abolished by $\mathrm{NAD}(\mathrm{P}) \mathrm{H}$-oxidase inhibition. Taken together, our data indicate that IL-17A causes the NAD(P)Hoxidase dependent generation of ROS leading to a proinflammatory activation of VSMC.
\end{abstract}

Copyright $\odot 2010$ S. Karger AG, Basel

\section{Introduction}

Increasing evidence supports the involvement of inflammation in the pathogenesis of atherosclerosis $[1,2]$. The pathogenic role of $\mathrm{T}$ cells in atherogenesis is well established, but the function of the various $T$ cell subsets is so far unclear. The activation of the T helper type 1 (Th1) subset promotes inflammatory and pro-atherogenic responses and activation of Th2 cells mediates both proatherogenic and anti-atherogenic effects $[3,4]$. The newly discovered IL-17-producing T cell subset (Th17) plays a major role in immune disease (rheumathoid arthritis, inflammatory bowel disease, multiple sclerosis) and seems to contribute to atherogenesis [5]. Very recently the presence of Th17 within atherosclerotic plaques of coronary arteries and elevated plasma levels of IL-17 in patients with acute myocardial infarction or unstable angina were observed [6, 7]. At the cellular level IL-17 has been demonstrated to induce a pro-inflammatory phenotype of vascular smooth muscle cells (VSMC) by enhancing the release of the pro-inflammatory mediators IL-6, CXCL8/10 and C-reactive protein involving p38 mitogen activated protein kinase (p38MAPK) signaling [7, 8].

Eweline Pietrowski and Bianca Bender contributed equally to this work.

\section{KARGER}

Fax +41613061234 E-Mail karger@karger.ch www.karger.com
Dr. Christoph R.W. Kuhlmann

Institute of Physiology and Pathophysiology

University Medical Center of the Johannes Gutenberg University

Duesbergweg 6, DE-55128 Mainz (Germany)

Tel. +496131 392 5771, Fax +496131 392 6071, E-Mail kuhlma@uni-mainz.de 
Since NAD $(\mathrm{P}) \mathrm{H}$-oxidase derived reactive oxygen species (ROS) are well known to promote atherogenesis [9], the aim of the present study was to investigate whether ROS are involved in the IL-17 dependent pro-inflammatory response of VSMC.

\section{Materials and Methods}

\section{Chemicals}

Calcein green, SB203580, SB202190, PD98059, SP600125, 2' 7'dichlorodihydrofluorescein $\left(\mathrm{H}_{2} \mathrm{DCF}\right)$, phosphate buffered saline (PBS), Hanks balanced salt solution (HBSS) and all other cell culture media (DMEM GlutaMAX I, F12 nutrient mixture), antibiotics (penicillin, streptomycin) and cell culture reagents (trypsin $0.05 \% / E D T A$ ) were obtained from Invitrogen (Karlsruhe, Germany). Fetal calf serum (FCS) was purchased from Biochrom (Berlin, Germany). Collagenase, elastase, trypsin inhibitor, apocynin, superoxide dismutase (SOD), catalase and recombinant IL17 were obtained from Sigma-Aldrich (Deisenhofen, Germany). Albumin fraction $\mathrm{V}$ was purchased from Carl Roth $\mathrm{GmbH}$ (Karlsruhe, Germany). $\mathrm{CaCl}_{2}$ was obtained from Riedel-de Haën (Seelze, Germany) and magnesium chloride hexahydrate was purchased from Merck (Darmstadt, Germany).

\section{Cell Isolation and Culture}

Murine aortic VSMC were isolated and cultured by a modification of the procedures described by Chamley-Campbell et al. [10]. In detail, male 6- to 12 -week-old C57BL/6 mice were sacrificed by $\mathrm{CO}_{2}$ asphyxia. The thoracic aorta from the descending thoracic aorta to the diaphragm as well as the abdominal aorta from the diaphragm to the renal artery branches were excised aseptically en bloc and placed in a petri dish containing ice-cold preparation solution (PBS with $\mathrm{Ca}^{2+}$ and $\mathrm{Mg}^{2+}, 5 \% \mathrm{FCS}, 50 \mu \mathrm{g} / \mathrm{ml}$ streptomycin, $50 \mathrm{U} / \mathrm{ml}$ penicillin). Remaining fat and connective tissue were removed by blunt dissection under a dissecting microscope and the vessel was flushed with fresh ice-cold preparation solution. The vessels were transferred into a $15-\mathrm{ml}$ plastic tube containing $4 \mathrm{ml}$ of prewarmed dissociation solution (Dulbecco's Modified Eagle Medium supplemented with $50 \mu \mathrm{g} / \mathrm{ml}$ streptomycin, $50 \mathrm{U} / \mathrm{ml}$ penicillin, $5 \mathrm{mmol} / \mathrm{l} \mathrm{Ca}^{2+}, 1.25 \mathrm{mg} / \mathrm{ml}$ collagenase from clostridium histolyticum type I, $0.1 \mathrm{mg} / \mathrm{ml}$ pancreatic elastase from porcine pancreas, $0.5 \mathrm{mg} / \mathrm{ml}$ trypsin inhibitor type I-S from soybean, $1 \mathrm{mg} / \mathrm{ml}$ bovine serum albumin fraction $\mathrm{V}$ ) and incubated for $30 \mathrm{~min}$ at $37^{\circ} \mathrm{C}$. After placing the aortas in fresh ice-cold preparation solution the adventitia was carefully removed under a microscope and the vessels were incubated again in fresh prewarmed dissociation solution for another $60 \mathrm{~min}$ at $37^{\circ} \mathrm{C}, 5 \% \mathrm{CO}_{2}$. After transferring the tissue to a fresh $8 \mathrm{ml}$ of dissociation solution the tubes were incubated for $3-4 \mathrm{~h}$ at $37^{\circ} \mathrm{C}, 5 \%$ $\mathrm{CO}_{2}$. The resulting cell-tissue suspension was titurated several times and the cell suspension was centrifuged for $5 \mathrm{~min}$ at $100 \mathrm{~g}$. The cells were resuspended in $15 \mathrm{ml}$ of VSMC medium [Dulbecco's Modified Eagle Medium GlutaMAX I/ F12 nutrient Mixture (Ham) containing 10\% FCS, 5\% horse serum, penicillin $100 \mathrm{U} / \mathrm{ml}$, streptomycin $100 \mu \mathrm{g} / \mathrm{ml}$ ] and incubated in a T75 culture flask at $37^{\circ} \mathrm{C}$ and $5 \% \mathrm{CO}_{2}$. After $24 \mathrm{~h}$ the cells were washed once with HBSS to remove nonadherent cells and debris and fed with pre- warmed fresh medium. Medium was routinely exchanged at $48-$ $72 \mathrm{~h}$ intervals thereafter. In all experiments, murine VSMC were used from passage $3-8$. In addition, primary cells were used for $\mathrm{H}_{2}$ DCF measurements.

\section{Detection of the IL-17A Receptor}

Total RNA from $2 \times 10^{6}$ VSMC was extracted using RNeasy Mini Kit (Qiagen). One $\mu \mathrm{g}$ total RNA was reverse transcribed using the SuperScript II reverse transcriptase (Invitrogen Life Technologies) according to the manufacturer's protocol using oligo $(\mathrm{DT})_{12-18}$ primer. cDNA was amplified with the following primers specific for IL-17A receptor (IL-17AR): 5'-GCAGCTGAACACCAATGAGC-3' and 5'-GCAGCACCAGTGAAACTTGC-3'.

\section{VSMC Proliferation and Migration}

VSMC proliferation was measured using a crystal violet assay. VSMC were seeded in a 96-well plate at a density of 10,000 cells per well. After $24 \mathrm{~h}$, standard culture medium was changed to medium containing $1 \%$ FCS and/or IL-17A (1-100 ng/ml) only. After $24 \mathrm{~h}$, cells were fixed and stained with crystal violet. After three washing steps, crystal violet absorption $(595 \mathrm{~nm})$ of the individual wells were measured using an InfiniteF200 plate reader (Tecan, Salzburg, Austria). The migration of VSMC was analyzed using the fences migration assay as described before [11]. Briefly, 5,000 VSMC per well were used in the fences assay. Similar to the proliferation assay, cells were kept in serum reduced medium and treated with IL-17A (50-100 ng/ml) for $24 \mathrm{~h}$. Thereafter, cells were stained using calcein green. Cell expansion was quantified using an InfiniteF200 plate reader.

\section{$\mathrm{H}_{2} \mathrm{DCF}$ Measurements}

The intracellular formation of ROS was examined using the ROS sensitive fluorescent dye $\mathrm{H}_{2} \mathrm{DCF}$, as described in more detail previously [12]. Cells were grown in 96-well plates until they reached confluence. VSMC were treated with IL-17A $(100 \mathrm{ng} / \mathrm{ml})$ for 3, 12 or $24 \mathrm{~h}$. During the last hour of IL-17A treatment, $\mathrm{H}_{2} \mathrm{DCF}$ was added to the medium at a concentration of $10 \mu \mathrm{mol} / \mathrm{l}$. Thereafter the medium was removed and the cells were washed three times with $\mathrm{HBSS}$ in order to remove free $\mathrm{H}_{2} \mathrm{DCF}$. The plates were transferred immediately to the above-mentioned plate reader and $\mathrm{H}_{2}$ DCF fluorescence was measured.

\section{NAD $(P) H$-Oxidase Activity Assay}

$\mathrm{NAD}(\mathrm{P}) \mathrm{H}$-oxidase activity was measured as described previously [13]. Briefly, VSMC were cultured in 96-well plates at a density of 20,000 cells per well. After $24 \mathrm{~h}$ the cells were treated with IL-17A (100 ng/ml) and or SB203580 (1 $\mu \mathrm{mol} / \mathrm{l})$ for $24 \mathrm{~h}$. Membrane fractions were obtained using a detergent digestion procedure [14]. $\mathrm{NAD}(\mathrm{P}) \mathrm{H}$-oxidase activity was measured by lucigenin chemiluminescence using the luminescence channel of a tecan InfiniteF200 plate reader [14].

\section{Nox mRNA Expression}

Total RNA was extracted from VSMC cells grown in 6-well dishes using the RNeasy Mini Kit (Qiagen) and $1 \mu \mathrm{g}$ of RNA was reverse transcribed with random hexameric primes using Transcriptor Reverse Transcriptase according to the manufacturer's protocol (Roche Applied Science). cDNA was amplified and detected with a LightCycler 1.5 System using the LightCycler TaqMan Master Kit and the Universal ProbeLibrary (UPL) System 
(both Roche Applied Science). Beta-Actin (ACTB) was used as a reference gene. The following primers and probes were used: Nox2: 5'-GCCTGCCTGAATTTCAACTG-3' and 5'-TGTCTTCGAATCCTTGTCGAG-3', UPL probe 74, Nox4: 5'-GAAGATTTGCCTGGAAGAACC-3' and 5'-AAGGCACAAAGGTCCAGAAA-3', UPL probe 85, ACTB: 5'-TGACAGGATGCAGAAGGAGA-3' and 5'-CGCTCAGGAGGAGCAATG, UPL probe 106. Relative expression was assessed based on the $\Delta \Delta \mathrm{Ct}$ method using REST Software [15].

siRNA Treatment

AllStars Negative Control siRNA, Nox2 (target sequence CAGTATCGGCACAGAAGTATA) and Nox4 (target sequence CAGGAATAAATTAAAGCTTTA) siRNA duplexes were purchased from Qiagen. VSMC cells grown in 24-well dishes were transfected with 20 pmol siRNA using FugeneHD transfection reagent (Roche Applied Science).

\section{Cytokine Release}

The release of pro-inflammatory cytokines from VSMC treated with IL-17A $(100 \mathrm{ng} / \mathrm{ml})$ was analyzed using the Luminex technology [16]. VSMC were cultured in 6-well plates until they reached confluence. Next, cells were treated with IL-17A and inhibitors for $24 \mathrm{~h}$.

\section{Statistical Analysis}

Results are represented as mean values \pm SEM. Statistical analysis was performed by ANOVA and post-hoc Tukey test using GraphPad Prism, Windows version 4.02 (GraphPad Software, San Diego, Calif., USA).

\section{Results}

\section{IL-17A Has No Effect on VSMC Proliferation or Migration}

The proliferation and migration of VSMC is a hallmark of atherosclerotic transformation of the vascular wall. Surprisingly, IL-17A had no effect on VSMC proliferation (fig. 1a) or migration (fig. 1b). To ensure that this effect is not due to the absence of the IL-17A receptor in our VSMC cultures we used RT-PCR to examine IL-17AR expression. As shown in a representative PCR gel (fig. 1c) VSMC express mRNA of the IL-17AR.

\section{IL-17A Induced ROS Formation Involves Nox2}

Mediated Activation of the NAD $(P) H$-Oxidase

The formation of ROS in VSMC was detected using the ROS sensitive fluorescent dye $\mathrm{H}_{2}$ DCF. IL-17A at a concentration of $100 \mathrm{ng} / \mathrm{ml}$ caused a significant increase of $\mathrm{H}_{2} \mathrm{DCF}$ fluorescence after an incubation period of 12 $24 \mathrm{~h}$ (fig. 2a). This effect could also be observed in primary cells [ROS production relative to control: $1.90 \pm$ 0.27 (passaged cells); $1.86 \pm 0.21$ (primary cells); $\mathrm{n}=4$ experiments; $\mathrm{p}=\mathrm{n} . \mathrm{s}$.] The $\mathrm{NAD}(\mathrm{P}) \mathrm{H}$-oxidase is a major
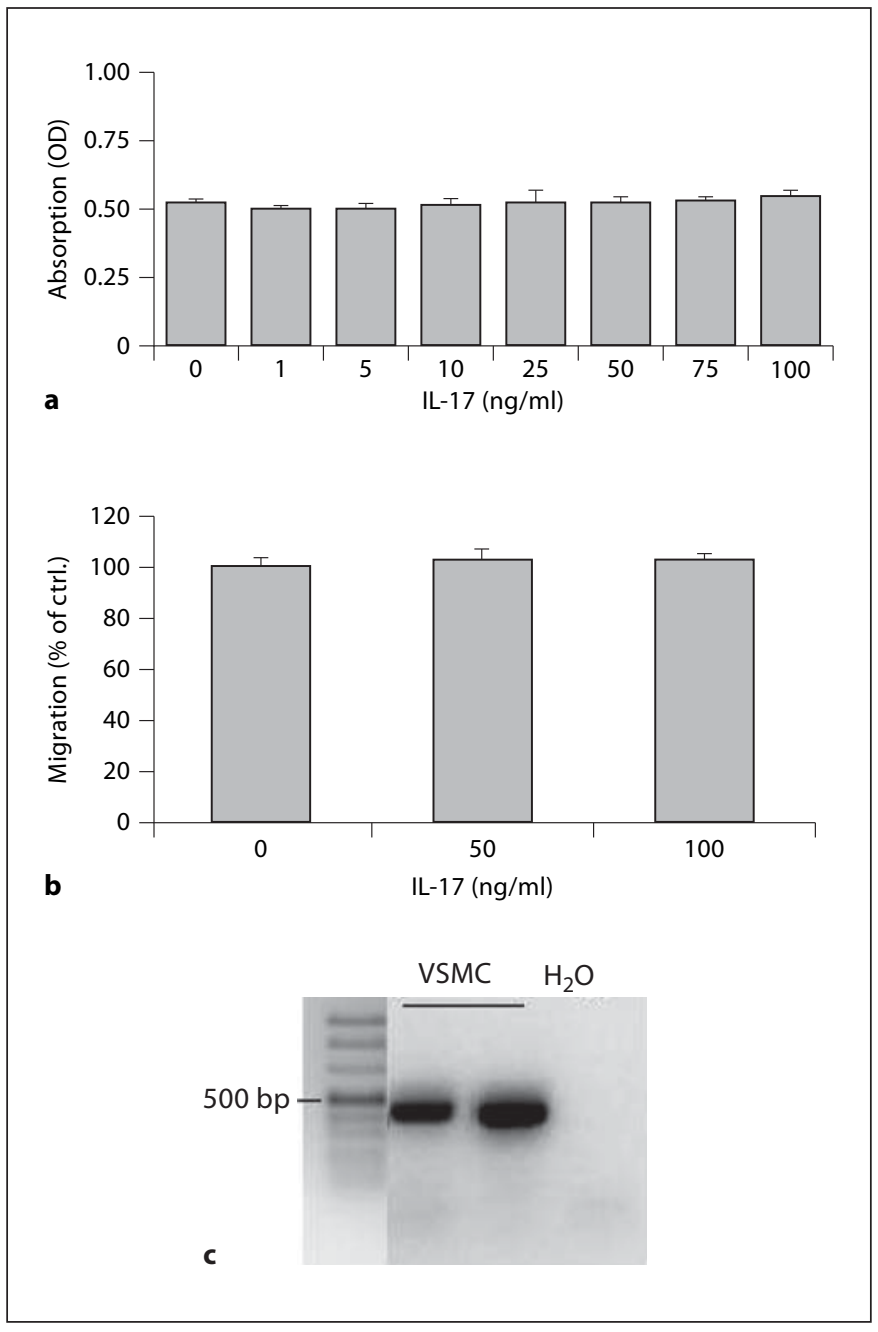

Fig. 1. No effect of IL-17A on VSMC proliferation or migration. The Effect of IL-17A (1-100 ng/ml) on VSMC proliferation (a) or migration (b) was examined using crystal violet staining and the fences migration assay, respectively. Data represent mean values \pm SEM of $n=4$ individual experiments. No significant effects compared to the vehicle treated control could be detected. The expression of the IL-17AR was examined using RT-PCR (c).

source of ROS in VSMC. For this reason we treated VSMC with the $\mathrm{NAD}(\mathrm{P}) \mathrm{H}$-oxidase inhibitor apocynin $(500$ $\mu \mathrm{mol} / \mathrm{l})$, which completely abolished IL-17A induced ROS (fig. 2b). Since the NAD(P)H-oxidase generates superoxide and hydrogen peroxide, we next examined which of these ROS is generated in response to IL-17A. Catalase and to a lesser extent SOD significantly reduced IL-17A induced ROS levels, indicating that both ROS species are produced by VSMC after IL-17A treatment (fig. 2b). Next we examined whether the effect of IL-17A 


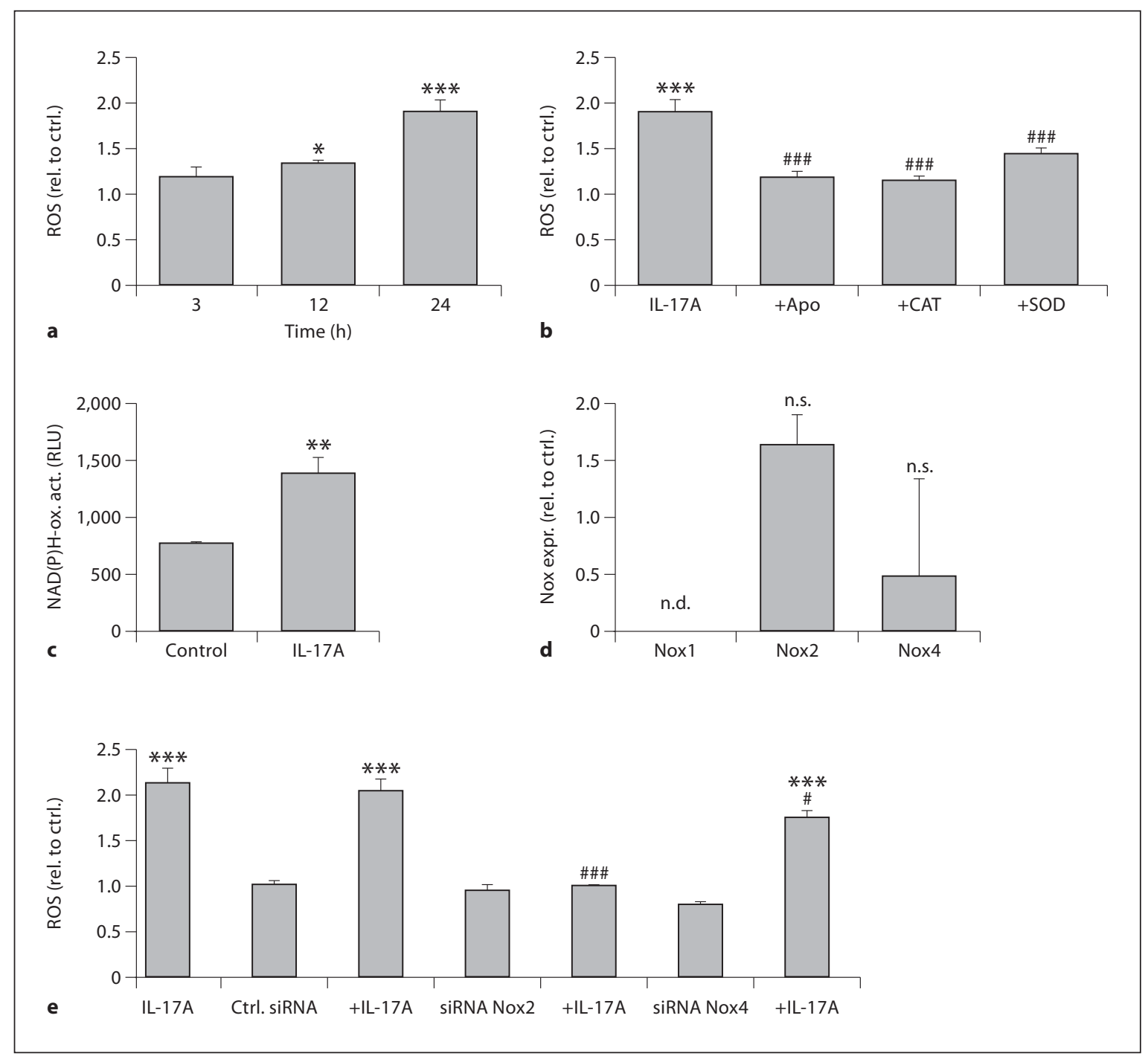

Fig. 2. IL-17A induced oxidative stress involves Nox 2 mediated activation of the NAD(P)H-oxidase. The generation of ROS was detected in cultured VSMC using the fluorescent dye $\mathrm{H}_{2} \mathrm{DCF}$. $\mathrm{H}_{2}$ DCF fluorescence of IL-17A $(100 \mathrm{ng} / \mathrm{ml})$ treated VSMC was set in relation to the vehicle treated control. The time dependent increase of IL-17A induced ROS formation (a) was reduced by apocynin (Apo; $500 \mu \mathrm{mol} / \mathrm{l})$, superoxide dismutase (SOD; $128 \mathrm{U} / \mathrm{ml}$ ) and catalase (CAT; $765 \mathrm{U} / \mathrm{ml})$ (b). c NAD(P)H-oxidase activity was examined in membrane fractions of IL-17A treated (100 ng/ $\mathrm{ml} ; 24 \mathrm{~h}$ ) VSMC using lucigenin chemiluminescence, presented as relative luminescence units (RLU). The mRNA expression of the
NAD(P)H-oxidase subunits Nox1, Nox2 and Nox4 was analyzed in VSMC by quantitative real time PCR after $24 \mathrm{~h} \mathrm{IL-17A} \mathrm{(100} \mathrm{ng/}$ ml) treatment. Expression levels of Nox 2 and Nox4 are given in relation to untreated VSMC. d No mRNA expression of Nox1 could be detected in untreated or IL-17A treated VSMC. e The effect of Nox 2 or Nox 4 directed siRNA treatment on IL-17A (100 ng/ml) induced ROS formation was analyzed by $\mathrm{H}_{2} \mathrm{DCF}$ fluorescence measurements. All data represent mean values \pm SEM of $\mathrm{n}=3$ (mRNA expression) or $\mathrm{n}=6$ individual experiments. ${ }^{*} \mathrm{p}<0.05,{ }^{* *} \mathrm{p}<0.01,{ }^{* * *} \mathrm{p}<0.001$ vs. control; ${ }^{\#} \mathrm{p}<0.05,{ }^{\# \#} \mathrm{p}<$ 0.001 vs. IL-17A without inhibitor or siRNA. is due to increased $\mathrm{NAD}(\mathrm{P}) \mathrm{H}$-oxidase activity, elevated Nox expression or both. NAD $(\mathrm{P}) \mathrm{H}$-oxidase activity was detected by lucigenin chemiluminescence and Nox expression levels by quantitative real-time PCR. VSMC treatment with IL-17A for $24 \mathrm{~h}$ caused a significant in- crease of $\mathrm{NAD}(\mathrm{P}) \mathrm{H}$-oxidase activity (fig. 2c), but did not change the mRNA expression levels of Nox 2 and Nox4 (fig. 2d). The mRNA expression of Nox1 could not be detected. Since apocynin does not provide any information regarding the Nox isoforms of the $\mathrm{NAD}(\mathrm{P}) \mathrm{H}$-oxidase that 


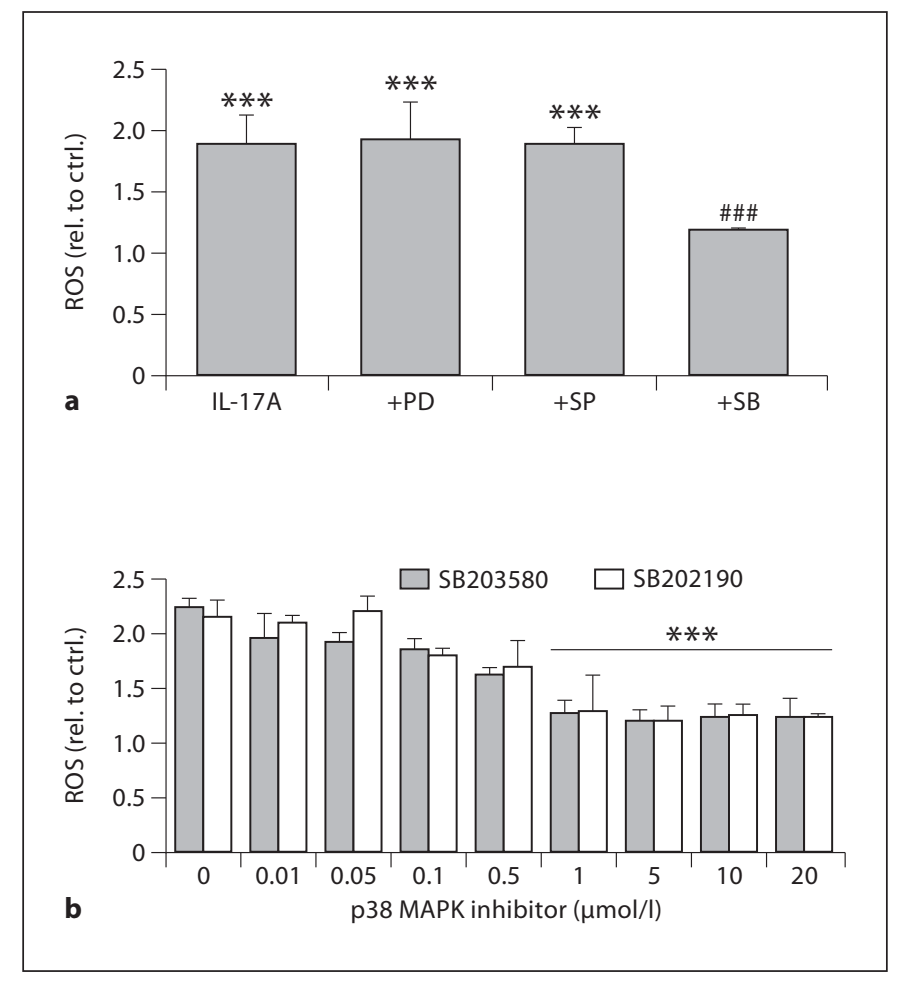

Fig. 3. IL-17A induced oxidative stress involves p38MAPK dependent activation of the NAD $(\mathrm{P}) \mathrm{H}$-oxidase. The generation of ROS was detected in cultured VSMC using the fluorescent dye $\mathrm{H}_{2}$ DCF. $\mathrm{H}_{2}$ DCF fluorescence of IL-17A (100 ng/ml) treated VSMC was set in relation to the vehicle treated control. The involvement of MAPK signaling was examined using SB203580 (20 $\mu \mathrm{mol} / \mathrm{l}$; p38MAPK), PD98059 (50 $\mu \mathrm{mol} / \mathrm{l}$; p42/44MAPK) or SP600125 $(20 \mu \mathrm{mol} / \mathrm{l}$; JNK) (a). The dose $(10 \mathrm{nmol} / \mathrm{l}-20 \mu \mathrm{mol} / \mathrm{l})$ dependent effect of the two chemically different p38MAPK inhibitors, SB203580 and SB202190, on IL-17A (100 ng/ml) induced ROS formation was examined in cultured VSMC (b). All data represent mean values \pm SEM of $\mathrm{n}=6$ individual experiments. ${ }^{*} \mathrm{p}<0.05$, ${ }^{* * *} \mathrm{p}<0.001$ vs. control; ${ }^{\# \#} \mathrm{p}<0.001$ vs. IL-17A without inhibitor.

are involved in IL-17A induced ROS generation, VSMC were treated with siRNA directed against the Nox2 and Nox4 isoform. Nox2 directed siRNA treatment resulted in a highly significant reduction of IL-17A induced ROS formation, whereas Nox 4 targeted siRNA application had only a moderate effect (fig. 2e).

\section{IL-17A Induced Oxidative Stress in VSMC Involves p38MAPK}

MAPK are well known to contribute to VSMC signaling. Addition of the p38MAPK inhibitor SB203580 (20 $\mu \mathrm{mol} / \mathrm{l}$ ) but not the inhibitors of the $\mathrm{p} 42 / 44 \mathrm{MAPK}$ (PD98059; $50 \mu \mathrm{mol} / \mathrm{l}$ ) or the JNK (SP600125; $20 \mu \mathrm{mol} / \mathrm{l})$ blocked IL-17A induced ROS formation in VSMC (fig. 3a). Since SB203580 at a concentration of $20 \mu \mathrm{mol} / \mathrm{l}$ may exert unspecific effects on other signaling pathways, a dose response curve $(10 \mathrm{nmol} / \mathrm{l}-20 \mu \mathrm{mol} / \mathrm{l})$ for SB203580 was performed. In order to strengthen the hypothesis that p38MAPK plays a critical role in IL-17A induced ROS formation, a second p38MAPK inhibitor (SB202190) was also used. As shown in figure $3 \mathrm{~b}$ both inhibitors caused a highly significant inhibition of IL-17A induced ROS formation already at a concentration of $1 \mu \mathrm{mol} / \mathrm{l}$. In addition, SB203580 at a concentration of $1 \mu \mathrm{mol} / \mathrm{l}$ caused a significant reduction of $\mathrm{NAD}(\mathrm{P}) \mathrm{H}$-oxidase activity (data given in relative luminescence units of lucigenin): control $765.23 \pm 21.96$; IL-17A 1,384.72 \pm 136.82; IL17-A + SB203580 893.11 \pm 77.49 ( $<<0.01$ IL-17A vs. control; $\mathrm{p}<0.01$ IL-17A vs. IL-17A + SB203580; $\mathrm{n}=4)$.

\section{Inhibition of the NAD $(P) H$-Oxidase Prevents IL-17A \\ Induced Cytokine Release}

The inflammatory response of VSMC to IL-17A (100 $\mathrm{ng} / \mathrm{ml} ; 24 \mathrm{~h}$ ) treatment was examined using the Luminex technology. The release of the following cytokines was measured in the supernatant: IL-6, MCP-1, GM-CSF, GCSF. As demonstrated in figure 4 the release of all cytokines was higher in IL-17A treated cells compared to vehicle treated controls. This effect was significantly reduced by the $\mathrm{NAD}(\mathrm{P}) \mathrm{H}$-oxidase inhibitor apocynin (500 $\mu \mathrm{mol} / \mathrm{l})$.

\section{Discussion}

The present study was performed to examine the contribution of oxidative stress to the pro-inflammatory effects of IL-17A in VSMC. The major findings of our study are: (1) IL-17A induces the $\mathrm{NAD}(\mathrm{P}) \mathrm{H}$-oxidase dependent generation of superoxide and hydrogen peroxide involving the Nox2 subunit; (2) inhibition of p38 MAPK signaling prevents IL-17A induced oxidative stress; (3) the IL17A induced ROS production is involved in the release of pro-inflammatory cytokines from VSMC.

Very recently a pro-atherosclerotic role of Th17 was proposed by Eid et al. [6]. They observed increased levels of IL-17A in patients and clinical specimens of coronary atherosclerosis. Furthermore, they could show in vitro increased levels of the pro-inflammatory cytokines IL-6, CXCL8 and CXCL10 released by VSMC in response to IL-17A. The role of IL-17A in coronary artery disease is further supported by a small clinical trial by Hashmi and Zeng [7]. In this study increased levels of IL-17, IL-6 and 


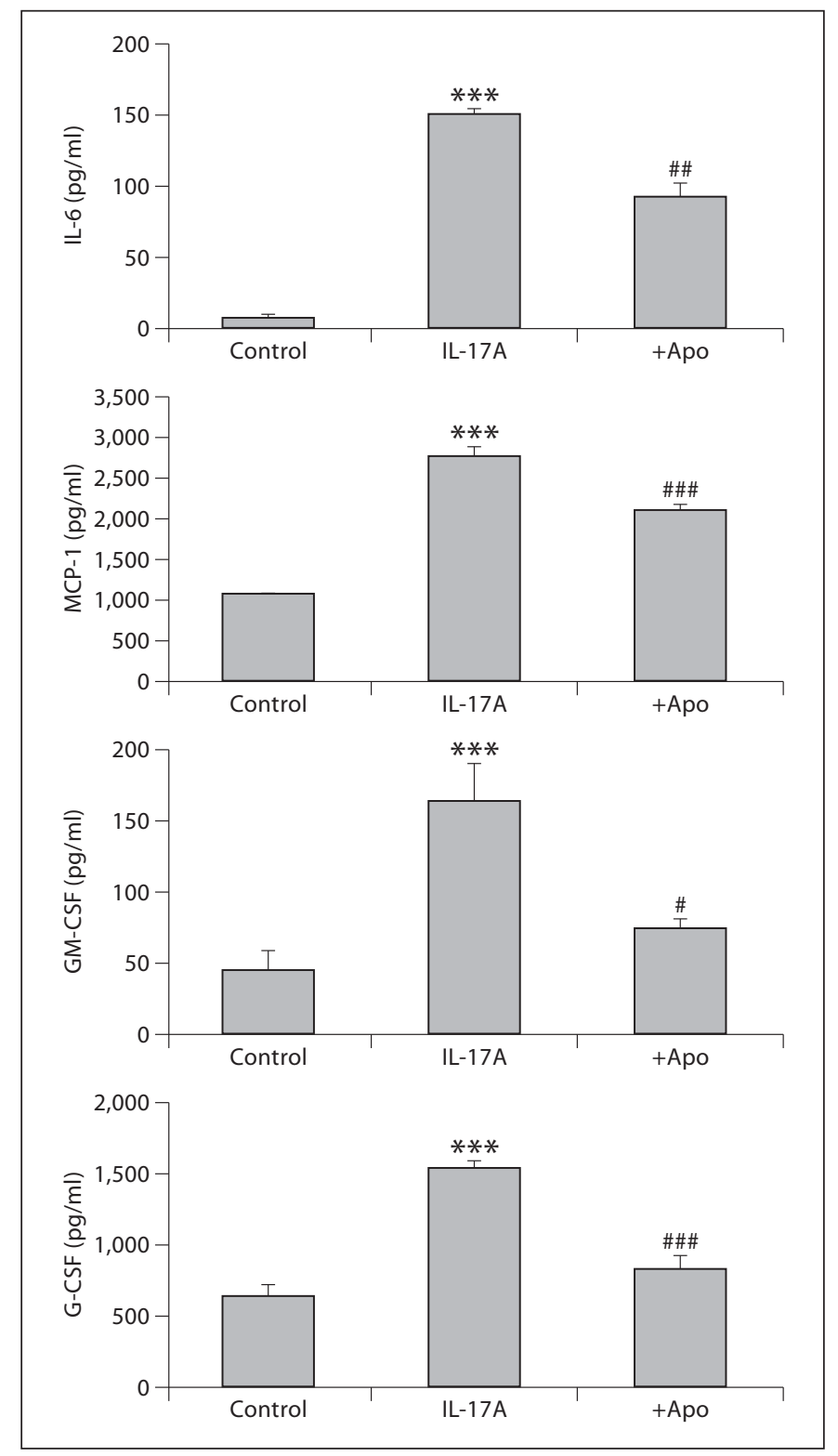

Fig. 4. Inhibition of the $\mathrm{NAD}(\mathrm{P}) \mathrm{H}$-oxidase prevents IL-17A induced release of pro-inflammatory mediators. The release of proinflammatory mediators upon IL-17A (100 ng/ml, $24 \mathrm{~h})$ and apocynin (Apo; $500 \mu \mathrm{mol} / \mathrm{l}$ ) treatment was examined in the supernatant of VSMC using the Luminex technology. Data represent mean values \pm SEM of $\mathrm{n}=3$ individual experiments. ${ }^{* *} \mathrm{p}<0.01,{ }^{* * *} \mathrm{p}<$ 0.001 vs. control; ${ }^{\#} \mathrm{p}<0.05,{ }^{\# \#} \mathrm{p}<0.01$, ${ }^{\# \#} \mathrm{p}<0.001$ vs. IL-17A.

IL-8 were found in patients with unstable angina or myocardial infarction. However, the mechanisms underlying the pro-inflammatory action of IL-17A are poorly understood. ROS produced by the $\mathrm{NAD}(\mathrm{P}) \mathrm{H}$-oxidase are a well accepted promoter of atherosclerotic lesions in the vascu- lar wall [9]. In the present study we were able to demonstrate that IL-17A induces increased levels of ROS in VSMC. We identified the NAD $(\mathrm{P}) \mathrm{H}$-oxidase as the source of this oxidative stress. The elevated levels of oxidative stress in VSMC are likely due to an increased $\mathrm{NAD}(\mathrm{P}) \mathrm{H}-$ oxidase activity, because activity levels were significantly increased whereas mRNA expression levels were not affected by IL-17A treatment for $24 \mathrm{~h}$. Furthermore, we were able to identify the Nox isoforms involved in IL-17A induced ROS formation. Neither primary nor passaged VSMC showed Nox1 expression, which is in line with the findings of Touyz et al. [17]. Nox2 and Nox4 expression could be detected in VSMC, but their expression levels were not changed by IL-17A treatment. In order to differentiate between the putative effects of Nox 2 and Nox4 on IL-17A induced ROS production, VSMC were treated with siRNA targeting Nox 2 or Nox4. Nox 2 siRNA treatment completely abolished IL-17A induced oxidative stress, whereas Nox4 siRNA treatment had only a minor effect. These findings are supported by studies of others describing Nox 2 as a Nox isoform that is able to generate ROS in a stimulus dependent manner, whereas Nox4 constitutively produces ROS [18-21]. It should be mentioned that the exact Nox expression patterns in VSMC are a matter of debate. Nox1 and Nox4 RNA expression has been demonstrated in VSMC from different vessels, whereas Nox2 RNA expression has been so far demonstrated in VSMC of resistance vessels [17, 19-21]. On protein level Nox 2 has been detected in aortic VSMC, whereas a report of Nox1 expression is still missing [20,22]. The finding that SOD and catalase reduce IL-17A dependent ROS formation is well in agreement with the findings of others. Dikalov et al. were able to demonstrate that angiotensin II induced activation of the $\mathrm{NAD}(\mathrm{P}) \mathrm{H}$-oxidase results in superoxide and hydrogen peroxide generation [23]. We next examined the contribution of MAPK signaling to IL-17A dependent ROS formation. Inhibition of the p38MAPK, but not of the p42/44MAPK or the JNK completely blocked IL-17A dependent ROS formation. This finding is well in line with the studies of Eid et al. and Patel et al. who were able to demonstrate a p38MAPK activation in human VSMC after IL-17A treatment $[6,8]$. Since it has been shown that IL-17A enhances the release of pro-inflammatory cytokines from VSMC, we next examined whether the inhibition of IL-17A induced ROS formation blocks the pro-inflammatory response of VSMC. We observed increased levels of the pluripotent pro-inflammatory cytokine IL-6 in response to IL-17A treatment. Furthermore the release of G-CSF, GM-CSF and of the chemokine MCP-1 was enhanced by IL-17A, 
indicating a potential role of IL-17A in recruiting further leukocytes to atherosclerotic plaques. These observations are in line with a very recent report of Erbel et al. [24]. They observed an increase of IL- 6 and MCP-1 release if cultured murine VSMC were treated with IL-17A. Application of the $\mathrm{NAD}(\mathrm{P}) \mathrm{H}$-oxidase inhibitor apocynin significantly reduced the IL-17A induced release of these cytokines. However, it should be mentioned that the effects of IL-17A on pro-inflammatory cytokine release were not completely abolished in our experiments. Other mecha- nisms such as $\mathrm{Nf} \kappa \mathrm{B}$ activation as observed in endothelial cells and macrophages may be also responsible for the effects observed in VSMC [24-26].

Taken together, the results of our present study demonstrate for the first time that p38MAPK dependent ROS formation of the $\mathrm{NAD}(\mathrm{P}) \mathrm{H}$-oxidase plays an essential role for the release of pro-inflammatory cytokines from VSMC. This signaling pathway might be a target for future therapeutic approaches to reduce the inflammatory burden in atherosclerotic lesions.

\section{References}

1 Ross R: Atherosclerosis: an inflammatory disease. N Engl J Med 1999;340:115-126.

$\checkmark 2$ Libby P: Inflammation in atherosclerosis. Nature 2002;420:868-874.

>3 Frostegård J, Ulfgren AK, Nyberg P, Hedin U, Swedenborg J, Andersson U, Hansson, GK: Cytokine expression in advanced human atherosclerotic plaques: dominance of pro-inflammatory (Th1) and macrophagestimulating cytokines. Atherosclerosis 1999; 145:33-43.

$\checkmark 4$ Robertson AK, Hansson GK: T cells in atherogenesis: for better or for worse? Arterioscler Thromb Vasc Biol 2006;26:2421-2432.

$\checkmark 5$ Weaver CT, Hatton RD, Mangan PR, Harrington LE: IL-17 family cytokines and the expanding diversity of effector T cell lineages. Annu Rev Immunol 2007;25:821-852.

-6 Eid RE, Rao DA, Zhou J, Lo SF, Ranjbaran H, Gallo A, Sokol SI, Pfau S, Pober JS, Tellides $\mathrm{G}$ : Interleukin-17 and interferon-gamma are produced concomitantly by human coronary artery-infiltrating T cells and act synergistically on vascular smooth muscle cells. Circulation 2009;119:1424-1432.

7 Hashmi S, Zeng QT: Role of interleukin-17 and interleukin-17-induced cytokinesinterleukin- 6 and interleukin- 8 in unstable coronary artery disease. Coron Artery Dis 2006;17:699-706.

$\checkmark 8$ Patel DN, King CA, Bailey SR, Holt JW, Venkatachalam K, Agrawal A, Valente AJ, Chandrasekar B: Interleukin-17 stimulates C-reactive protein expression in hepatocytes and smooth muscle cells via p38 MAPK and ERK1/2-dependent NF-kappaB and C/EBPbeta activation. J Biol Chem 2007;282: 27229-27238

9 Griendling KK, Sorescu D, Ushio-Fukai M: NAD(P)H oxidase: role in cardiovascular biology and disease. Circ Res 2000;86:494501.

-10 Chamley-Campbell JH, Campbell GR, Ross $\mathrm{R}$ : Phenotype-dependent response of cultured aortic smooth muscle to serum mitogens. J Cell Biol 1981;89:379-383.
11 Kuhlmann CR, Schaefer CA, Reinhold L, Tillmanns H, Erdogan A: Signalling mechanisms of SDF-induced endothelial cell proliferation and migration. Biochem Biophys Res Commun 2005;335:1107-1114.

12 Huppert J, Closhen D, Croxford A, White R, Kulig P, Pietrowski E, Bechmann I, Becher B, Luhmann HJ, Waisman A, Kuhlmann CR: Cellular mechanisms of IL-17-induced blood-brain barrier disruption. FASEB J 2009;24:1023-1034.

13 Kuhlmann CR, Gerigk M, Bender B, Closhen D, Lessmann V, Luhmann HJ: Fluvastatin prevents glutamate-induced blood-brainbarrier disruption in vitro. Life Sci 2008;82: 1281-1287.

14 Garcia-Garcia E, Andrieux K, Gil S, Kim HR, Le Doan T, Desmaële D, d'Angelo J, Taran F, Georgin D, Couvreur P: A methodology to study intracellular distribution of nanoparticles in brain endothelial cells. Int J Pharm 2005;298:310-314.

15 Liu MY, Xydakis AM, Hoogeveen RC, Jones PH, Smith EO, Nelson KW, Ballantyne CM: Multiplexed analysis of biomarkers related to obesity and the metabolic syndrome in human plasma, using the Luminex-100 system. Clin Chem 2005;51:1102-1109.

16 Pfaffl MW, Horgan GW, Dempfle L: Relative expression software tool (REST@) for groupwise comparison and statistical analysis of relative expression results in real-time PCR. Nucleic Acids Res 2002;30:e36.

17 Touyz RM, Chen X, Tabet F, Yao G, He G, Quinn MT, Pagano PJ, Schiffrin EL: Expression of a functionally active gp91phox-containing neutrophil-type $\mathrm{NAD}(\mathrm{P}) \mathrm{H}$ oxidase in smooth muscle cells from human resistance arteries: regulation by angiotensin II. Circ Res 2002;90:1205-1213.

18 Shiose A, Kuroda J, Tsuruya K, Hirai M, Hirakata $H$, Naito $S$, Hattori M, Sakaki Y, Sumimoto $\mathrm{H}$ : A novel superoxide-producing $\mathrm{NAD}(\mathrm{P}) \mathrm{H}$ oxidase in kidney. J Biol Chem 2001;276:1417-1423.
19 Lassègue B, Sorescu D, Szöcs K, Yin Q, Akers M, Zhang Y, Grant SL, Lambeth JD, Griendling KK: Novel gp91 (phox) homologues in vascular smooth muscle cells: nox 1 mediates angiotensin II-induced superoxide formation and redox-sensitive signaling pathways. Circ Res 2001;88:888-894.

20 Kalinina N, Agrotis A, Tararak E, Antropova Y, Kanellakis P, Ilyinskaya O, Quinn MT, Smirnov V, Bobik A: Cytochrome b558-dependent $\mathrm{NAD}(\mathrm{P}) \mathrm{H}$ oxidase-phox units in smooth muscle and macrophages of atherosclerotic lesions. Arterioscler Thromb Vasc Biol 2002;22:2037-2043.

-21 Sorescu D, Weiss D, Lasse'gue B, Clempus RE, Szöcs K, Sorescu GP, Valppu L, Quinn MT, Lambeth JD, Vega JD, Taylor WR, Griendling KK: Superoxide production and expression of nox family proteins in human atherosclerosis. Circulation 2002;105:14291435 .

22 Lassegue B, Clempus RE: Vascular NAD (P)H oxidases: specific features, expression, and regulation. Am J Physiol Regul Integr Comp Physiol 2003;285:277-297.

23 Dikalov SI, Dikalova AE, Bikineyeva AT, Schmidt HH, Harrison DG, Griendling KK: Distinct roles of Noxl and Nox4 in basal and angiotensin II-stimulated superoxide and hydrogen peroxide production. Free Radic Biol Med 2008;45:1340-1351.

24 Erbel C, Chen L, Bea F, Wangler S, Celik S, Lasitschka F, Wang Y, Böckler D, Katus HA, Dengler TJ: Inhibition of IL-17A attenuates atherosclerotic lesion development in apoEdeficient mice. J Immunol 2009;183:81678175.

25 Jovanovic DV, Di Battista JA, Martel-Pelletier J, Jolicoeur FC, He Y, Zhang M, Mineau F, Pelletier JP: IL-17 stimulates the production and expression of proinflammatory cytokines, IL- $\beta$ and TNF $\alpha$, by human macrophages. J Immunol 1998;160:3513-3521.

26 Schwandner R, Yamaguchi K, Cao Z: Requirement of tumor necrosis factor receptorassociated factor (TRAF)6 in interleukin 17 signal transduction. J Exp Med 2000;191: $1233-1240$. 